\title{
Closeness Degree-Based Hesitant Trapezoidal Fuzzy Multicriteria Decision Making Method for Evaluating Green Suppliers with Qualitative Information
}

\author{
Xiaolu Zhang $\mathbb{D}^{1},{ }^{1}$ Touping Yang, ${ }^{1}$ Wei Liang, ${ }^{1}$ and Meifang Xiong ${ }^{2}$ \\ ${ }^{1}$ The Collaborative Innovation Center, Jiangxi University of Finance and Economics, Nanchang 330013, China \\ ${ }^{2}$ College of Modern Economics \& Management, Jiangxi University of Finance and Economics, Nanchang 330013, China \\ Correspondence should be addressed to Xiaolu Zhang; xiaolu_jy@163.com
}

Received 1 November 2017; Accepted 15 March 2018; Published 22 April 2018

Academic Editor: Alicia Cordero

Copyright (c) 2018 Xiaolu Zhang et al. This is an open access article distributed under the Creative Commons Attribution License, which permits unrestricted use, distribution, and reproduction in any medium, provided the original work is properly cited.

\begin{abstract}
The aim of this study is to develop a new closeness degree-based hesitant trapezoidal fuzzy (HTrF) multicriteria decision making (MCDM) approach for identifying the most appropriate green suppliers in food supply chain involving uncertain qualitative evaluation information. The uniqueness of the proposed HTrF MCDM method is the consideration of uncertain qualitative information represented by flexible linguistic expressions based on $\mathrm{HTrF}$ values and the construction of compromise solution with the revised closeness degree. The revised closeness degree can make sure that the most appropriate solution has the shortest distance from the HTrF positive ideal solution and the farthest distance from the HTrF negative ideal solution, simultaneously. This proposed HTrF MCDM technique not only offers a simple and efficient decision support tool to aid the food firms for identifying the optimal suppliers in food supply chain but also can enable the managers of food firms to better understand the complete evaluation and decision processes. In addition, this study provides a novel defuzzification technique to manage the HTrF weights values of main-criteria and subcriteria, respectively.
\end{abstract}

\section{Introduction}

Today's food industry is more highly pressured from socially aware organizations and governments owing to various impacts in terms of ecological consumption and food production $[1,2]$. Most food companies intend to cooperate with excellent green suppliers in order to improve their competitive advantages and profits in recent years. The selection of green suppliers has been considered as a key activity in food supply chain owing to the fact that low quality and/or delayed delivery caused by suppliers make the product useless or expired. In practice, the selection of suppliers in food supply chain is a typical multicriteria decision making (MCDM) issue [3], which takes into account not only the traditional economic factors like cost, quality, and so on, but also the relevant environmental factors, like food safety, energy consumption, and so on. To adequately solve various actual decision making problems, many prominent MCDM approaches including the TOPSIS $[4,5]$, the PROMETHEE method [6], and the QUALIFLEX [7, 8] have been developed during the past decade. As one of the most popular MCDM methods, the TOPSIS approach which ranks objects based on closeness degrees, according to the principle that the best objects should have the shortest distance from positive ideal solutions (PISs) and the farthest distance from negative ideal solutions (NISs) [4], has successfully been applied in realworld MCDM problems including the selection of suppliers $[9,10]$, performance measurement [11], the selection of plant location [12, 13], personnel selection [14], the risk assessment of bridges [15], and customer evaluation [16].

However, it is very common in the evaluating and ranking process that the evaluators prefer to employ flexible linguistic expressions (FLEs) to express their opinions. For instance, the evaluator may utilize FLEs like "between middle and high" to express his/her opinion when assessing the delivery capacity of a green supplier. The use of FLEs to present the uncertain 
qualitative information greatly increases the accuracy of the assignment of criteria weights and criteria values in the evaluating process [17]. Although many extension forms of TOPSIS approach, including hesitant fuzzy TOPSIS [18], intuitionistic fuzzy TOPSIS [9], Pythagorean fuzzy TOPSIS [19], interval-valued intuitionistic fuzzy TOPSIS [20, 21], hesitant fuzzy linguistic TOPSIS [22], and so on, have recently been developed to handle the MCDM issues with different fuzzy environments, these existing techniques fail to deal with the MCDM issues where the decision data are represented by FLEs. To this end, this paper attempts to develop a new closeness degree-based hesitant trapezoidal fuzzy (HTrF) MCDM method which absorbs the advantages of HTrF values and inherits the feature of the classical TOPSIS approach simultaneously [17].

To do this, the HTrF values are first presented to capture the uncertainty of FLEs. The HTrF values possess the advantage of trapezoidal fuzzy numbers (TrFNs) and the superiority of hesitant fuzzy elements [23] is able to capture the vague information in various uncertain MCDM issues. Afterwards, HTrF PIS and HTrF NIS are identified by using the comparative method of HTrF values, respectively. What is more, a new defuzzification technique for HTrF values is introduced to manage the HTrF weight values of the maincriteria and the subcriteria. Finally, the optimal suppliers are selected where they have the shortest distance from HTrF PIS and the farthest distance from HTrF NIS, synchronously. The remainder of this work is organized as follows: Section 2 reviews briefly the definition of fuzzy linguistic approach and the basic concepts of HTrF values, Section 3 develops a new closeness degree-based HTrF MCDM approach, Section 4 discusses a case study by using the developed method, and conclusions are made in Section 5.

\section{Preliminaries}

This section recalls briefly the definition of fuzzy linguistic approach and the basic concepts of HTrF values.

One label set $L=\left\{l_{i} \mid i=0,1, \ldots, u\right\}$ is called a linguistic variable if its element $l_{i}$ satisfies the following conditions: (1) $l_{i} \geq l_{j}(i, j=0,1, \ldots, u)$, if $i \geq j ;(2)$ negation operator $N\left(l_{i}\right)=$ $l_{j}$, if $j=u-i$ [24]. In many practical evaluation processes, the evaluators may employ the predefined linguistic terms to express their uncertain preference. For example, based on one predefined seven-point rating scale linguistic term set (LTS) $L=\left\{l_{0}\right.$ (very poor), $l_{1}$ (poor), $l_{2}$ (medium poor), $l_{3}$ (fair), $l_{4}$ (medium good), $l_{5}$ (good), $l_{6}$ (very good) $\}$, the evaluators may employ the linguistic term like $l_{5}$ (good) or $l_{1}$ (poor) to assess the comfort degree of one car. However, it is worth noting that in some complex MCDM processes the use of the single linguistic term to model the uncertainty related to the qualitative nature may restrict the evaluators to utilize more rich expressions to represent their preferences. For instance, in the evaluation of air emission of green suppliers in food supply chain, the assessors cannot easily provide a single linguistic term like $l_{5}$ to represent their imprecise opinions but may prefer to use FLEs like at least $l_{5}$ or between $l_{3}$ and $l_{5}$.

To facilitate computing with words, Rodriguez et al. [25] introduced the definition of hesitant fuzzy LTS. Hesitant fuzzy LTS is one ordered finite subset of consecutive linguistic terms of a predefined LTS, which is represented mathematically by $H_{L}=\left\{l_{i}, l_{i+1}, \ldots, l_{j}\right\}$ and $l_{k} \in L(k=i, i+1, \ldots, j)$. For example, based on one aforementioned LTS $L, H_{L}^{1}=\left\{l_{0}, l_{1}, l_{2}\right\}$ and the $H_{L}^{2}=\left\{l_{2}, l_{3}\right\}$ are two different hesitant fuzzy LTSs. According to the study of Rodriguez et al. [25], FLEs can be mathematically equivalent to the hesitant fuzzy LTSs based on the following transformation function TF:

$$
\begin{gathered}
\operatorname{TF}\left(l_{i}\right)=\left\{l_{i} \mid l_{i} \in L\right\}, \\
\operatorname{TF}\left(\text { at most } l_{i}\right)=\left\{l_{j} \mid l_{j} \leq l_{i}, l_{i}, l_{j} \in L\right\}, \\
\operatorname{TF}\left(\text { at least } l_{i}\right)=\left\{l_{j} \mid l_{j} \geq l_{i}, l_{i}, l_{j} \in L\right\}, \\
\operatorname{TF}\left(\text { between } l_{i}, l_{j}\right)=\left\{l_{k} \mid l_{i} \leq l_{k} \leq l_{j}, l_{i}, l_{k}, l_{j} \in L\right\} .
\end{gathered}
$$

Namely, according to the function TF two FLEs $\mathrm{fl}_{1}=$ at most $l_{2}$ \} and $\mathrm{fl}_{2}=$ \{between $l_{1}$ and $\left.l_{3}\right\}$ can be mathematically equivalent to the following two hesitant fuzzy LTSs $H_{L}^{1}=\operatorname{TF}\left(\mathrm{fl}_{1}\right)=\left\{l_{0}, l_{1}, l_{2}\right\}$ and $H_{L}^{2}=\operatorname{TF}\left(\mathrm{fl}_{2}\right)=\left\{l_{1}, l_{2}, l_{3}\right\}$, respectively.

Remark 1. It is noted that the single linguistic term is one special case of FLEs and hesitant fuzzy LTS.

To capture the semantics of single linguistic term assessments in decision making processes, one of the well-known linguistic computing techniques is the use of TrFNs. One fuzzy number $\widetilde{\alpha}=T(a, b, c, d)(a \leq b \leq c \leq d)$ is said to be a TrFN if its membership function is given as follows [26]:

$$
\mu_{\widetilde{\alpha}}(x)= \begin{cases}\frac{(x-a)}{(b-a)}, & (a \leq x<b) \\ 1, & (b \leq x \leq c) \\ \frac{(d-x)}{(d-c)}, & (c<x \leq d) \\ 0, & \text { otherwise. }\end{cases}
$$

A widely used seven-point rating scale-based linguistic rating system based on TrFNs is introduced as in Figure 1. For example, according to this linguistic rating system in Figure 1, the performance of one supplier under the criterion provided by the evaluator is "Good." The semantic of the linguistic evaluation value "Good" can be modeled by the TrFN $T(0.7,0.8,0.8,0.9)$.

Although TrFNs can well capture the vagueness of single linguistic term assessments, they fail to represent the vagueness of FLEs. By integrated hesitant fuzzy elements into TrFNs, Zhang et al. [17] recently provided a novel notion of the HTrF value for representing the vagueness of FLEs based on hesitant fuzzy LTSs.

Definition 2. Given a fixed set $X$, a HTrF set $H_{T}$ on $X$ is defined as

$$
H_{T}=\left\{\left\langle x, \widetilde{h}_{H_{T}}(x)\right\rangle \mid x \in X\right\}
$$




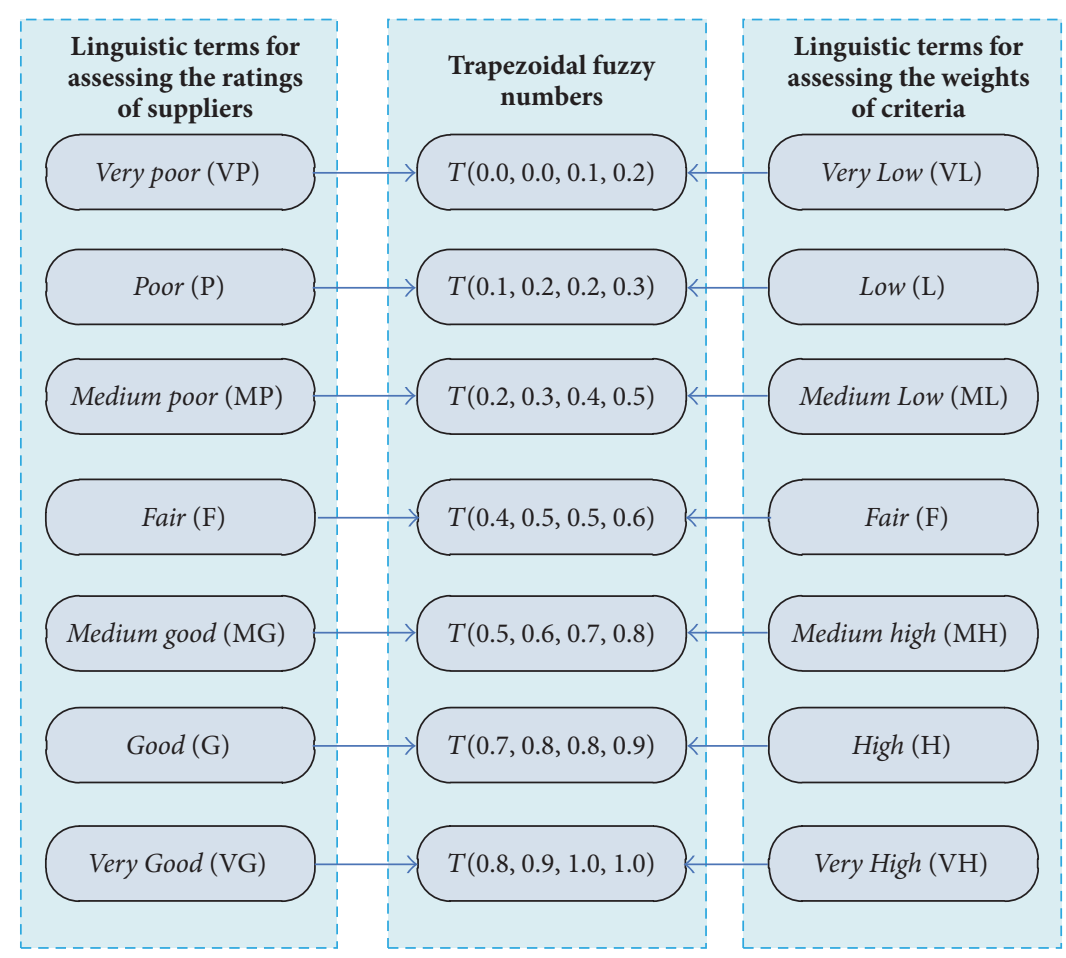

FIGURE 1: A seven-point rating scale-based linguistic rating system based on TrFNs.

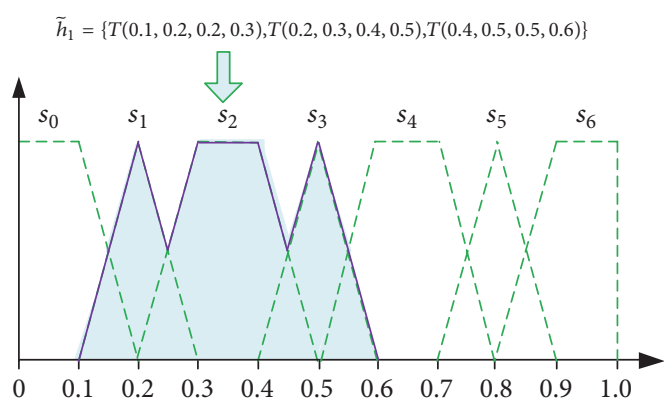

Figure 2: The HTrF semantic of the FLE $\mathrm{fl}_{1}=$ \{between $l_{1}$ and $\left.l_{3}\right\}$.

where $\widetilde{h}_{H_{T}}(x)$ is a set of different normalized TrFNs (a TrFN $\widetilde{\alpha}=T(a, b, c, d)$ is the normalized TrFN if $a \geq 0$ and $d \leq 1)$ used to represent the possible membership degrees of the element $x \in X$ to $H_{T}$. Usually, $\widetilde{h}_{H_{T}}(x)$ is called an $\mathrm{HTrF}$ value/number and denoted by $\widetilde{h}=\left\{\widetilde{\alpha}^{f} \mid f=1,2, \ldots, \# \widetilde{h}\right\}$ for simplification [17]. Each element $\widetilde{\alpha}_{f}=T\left(a^{f}, b^{f}, c^{f}, d^{f}\right)$ in $\widetilde{h}$ is the normalized TrFN and $\# \widetilde{h}$ is the number of all TrFNs in $\widetilde{h}$.
Example 3. On the basis of the linguistic rating system provided in Figure 1, one FLE is given as $\mathrm{fl}_{1}=$ \{between $l_{1}$ and $\left.l_{3}\right\}$; it is easily observed that the vagueness of this FLE can be modeled by the following $\operatorname{HTrF}$ number $\widetilde{h}_{1}$ :

$$
\begin{aligned}
\mathrm{fl}_{1} & \left(=\left\{\text { between } l_{1}, l_{3}\right\}\right) \stackrel{\mathrm{TF}\left(\mathrm{f}_{1}\right)}{\longrightarrow} H_{L}^{1}\left(=\left\{l_{1}, l_{2}, l_{3}\right\}\right) \longrightarrow \\
\widetilde{h}_{1}(=\{T(0.1,0.2,0.2,0.3), T(0.2,0.3,0.4,0.5), & \\
& T(0.4,0.5,0.5,0.6)\}) .
\end{aligned}
$$

Figure 2 shows this result graphically.

Next, we present a new general form of HTrF distance measures.

Definition 4. Given two HTrF numbers $\widetilde{h}_{i}=\left\{\tilde{\alpha}_{i}^{f}=\right.$ $\left.T\left(a_{i}^{f}, b_{i}^{f}, c_{i}^{f}, d_{i}^{f}\right) \mid f=1,2, \ldots, \# \widetilde{h}_{i}\right\}(i=1,2)$ with $\# \widetilde{h}=$ $\# \widetilde{h}_{1}=\# \widetilde{h}_{2}$, the general form of HTrF distance measure between them is defined as follows:

$$
d_{G}\left(\widetilde{h}_{1}, \widetilde{h}_{2}\right)=\left(\frac{1}{6 \# \widetilde{h}}\left(\sum_{f=1}^{\# \widetilde{h}}\left(\left|a_{1}^{f}-a_{2}^{f}\right|^{\lambda}+2\left|b_{1}^{f}-b_{2}^{f}\right|^{\lambda}+2\left|c_{1}^{f}-c_{2}^{f}\right|^{\lambda}+\left|d_{1}^{f}-d_{2}^{f}\right|^{\lambda}\right)\right)\right)^{1 / \lambda} .
$$

It is easy to see that this general form can be reduced into the HTrF Hamming distance introduced in [17] when $\lambda=1$ as

$$
d_{H}\left(\widetilde{h}_{1}, \widetilde{h}_{2}\right)=\frac{1}{6 \# \widetilde{h}}\left(\sum _ { f = 1 } ^ { \# \widetilde { h } } \left(\left|a_{1}^{f}-a_{2}^{f}\right|+2\left|b_{1}^{f}-b_{2}^{f}\right|\right.\right.
$$




$$
\left.\left.+2\left|c_{1}^{f}-c_{2}^{f}\right|+\left|d_{1}^{f}-d_{2}^{f}\right|\right)\right)
$$

and the HTrF Euclidean distance introduced in [17] when $\lambda=$ 2 as

$$
d_{E}\left(\widetilde{h}_{1}, \widetilde{h}_{2}\right)=\sqrt{\frac{1}{6 \# \tilde{h}}\left(\sum_{f=1}^{\# \tilde{h}}\left(\left(a_{1}^{f}-a_{2}^{f}\right)^{2}+2\left(b_{1}^{f}-b_{2}^{f}\right)^{2}+2\left(c_{1}^{f}-c_{2}^{f}\right)^{2}+\left(d_{1}^{f}-d_{2}^{f}\right)^{2}\right)\right)} .
$$

In the process of calculating the distance between two $\mathrm{HTrF}$ values, the numbers of TrFNs in these two HTrF numbers are required to be the same. However, the numbers of elements in different HTrF numbers are usually different. To achieve this goal, Zhang et al. [17] stipulated that the optimists usually add the maximum TrFN in the shorter one and the pessimists usually add the minimum TrFN. For convenience, it is assumed in this study that all possible TrFNs of HTrF numbers are arranged in increasing order and the evaluators are pessimists. The case that the assessors are optimists can be analyzed analogously.

Afterwards, Zhang et al. [17] presented a useful ranking approach of HTrF numbers.

Definition 5 (see [17]). Given an HTrF number $\widetilde{h}=\left\{T\left(a^{f}, b^{f}\right.\right.$, $\left.\left.c^{f}, d^{f}\right) \mid f=1,2, \ldots, \# \tilde{h}\right\}$ and one ideal HTrF number $\widetilde{h}^{*}=$ $\{T(1,1,1,1), T(1,1,1,1), \ldots, T(1,1,1,1)\}$, the HTrF distance between $\widetilde{h}$ and $\widetilde{h}^{*}$ is calculated as

$$
d_{S}\left(\widetilde{h}, \widetilde{h}^{*}\right)=\frac{1}{6 \# \tilde{h}} \sum_{f=1}^{\# \tilde{h}}\left(6-a^{f}-2 b^{f}-2 c^{f}-d^{f}\right)
$$

which is called HTrF sign distance in [17].

Based on the definition of $\mathrm{HTrF}$ sign distance, the ranking technique of HTrF values is introduced as follows: $\widetilde{h}_{1}$ is superior to $\widetilde{h}_{2}$ when the value of $d_{S}\left(\widetilde{h}_{1}, \widetilde{h}^{*}\right)$ is less than the value of $d_{S}\left(\widetilde{h}_{2}, \widetilde{h}^{*}\right)$; and similarly $\widetilde{h}_{1}$ is inferior to $\widetilde{h}_{2}$ when the value of $d_{S}\left(\widetilde{h}_{1}, \widetilde{h}^{*}\right)$ is bigger than the value of $d_{S}\left(\widetilde{h}_{2}, \widetilde{h}^{*}\right)$; and $\widetilde{h}_{1}$ is similar to $\widetilde{h}_{2}$ when the value of $d_{S}\left(\widetilde{h}_{1}, \widetilde{h}^{*}\right)$ is equal to the value of $d_{S}\left(\widetilde{h}_{2}, \widetilde{h}^{*}\right)$.

\section{Developed Hesitant Trapezoidal Fuzzy MCDM Approach}

The goal of this section is to develop a new HTrF MCDM technique for solving the selection issue of green suppliers in food supply chain in which the decision data take the form of FLEs. Before going into detail, we first present the background of the developed HTrF MCDM method, namely, the evaluating framework of suppliers in food supply chain.

3.1. Background to the Developed HTrF MCDM Method. Owing to the fact that low quality and/or delayed delivery caused by suppliers make the food product useless or expired, the selection of green suppliers has been considered as a key activity in food supply chain. Today's food firms have to carefully consider the relevant environmental factors like energy consumption along with the traditional economic factors like cost in the evaluation and selection process of green suppliers [27]. The suppliers which possess the advantages in environmental criteria and economic criteria, two aspects, should be greatly favored in food supply chain. According to the study of Govindan et al. [1], the performance evaluation of green suppliers in food supply chain usually requires food firms to take into account the following five main-criteria and a series of the corresponding subcriteria, like the quality assurance and reject rate in terms of quality criterion, the product price and logistic cost in terms of cost criterion, the food safety and energy consumption in terms of environmental impacts criterion, and so on. The selection framework of green suppliers in food supply chain is shown in Figure 3.

Referring to the hierarchy structure in Figure 3, there are $m$ qualified suppliers $\left\{A_{1}, A_{2}, \ldots, A_{m}\right\}$ and five assessed main-criteria $\left\{C_{1}, C_{2}, C_{3}, C_{4}, C_{5}\right\}$. Each main-criterion $C_{j}(j \in\{1,2,3,4,5\})$ includes $\# C_{j}$ subcriteria $\left\{C_{j(1)}, C_{j(2)}\right.$, $\left.\ldots, C_{j\left(\# C_{j}\right)}\right\}$, where $\# C_{j}$ denotes the number of subcriteria in the main-criterion $C_{j}$. The criterion value of the green supplier $A_{i}$ under the subcriterion $C_{j(k)}$ provided by the evaluator takes the form of FLE and is represented by $\mathrm{fl}_{i j(k)}$. The weight of the main-criteria $C_{j}(j \in\{1,2,3,4,5\})$ also takes the form of FLE and is represented by $w\left(C_{j}\right)$, and the weight of the subcriteria $C_{j(k)}\left(k \in\left\{1,2, \ldots, \# C_{j}\right\}\right)$ is represented by FLE and is denoted by $w\left(C_{j(k)}\right)$. Then, the decision data are mathematically represented by the following FLE decision matrix $\mathbf{f l}$ :

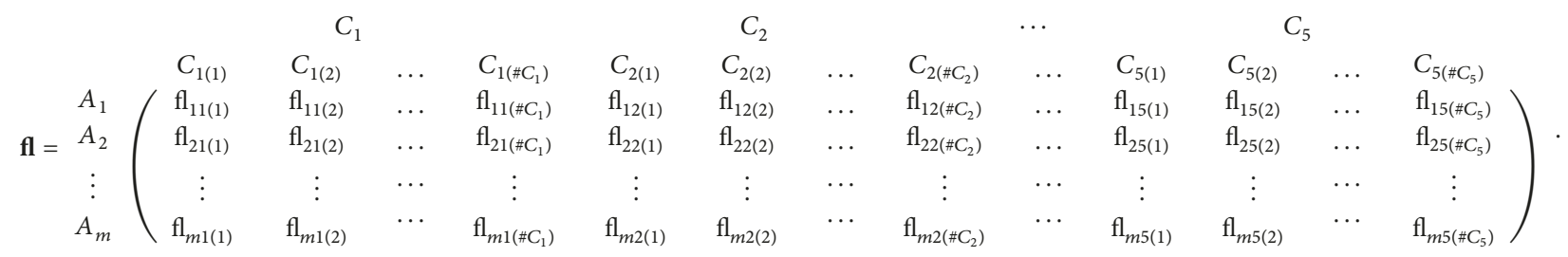




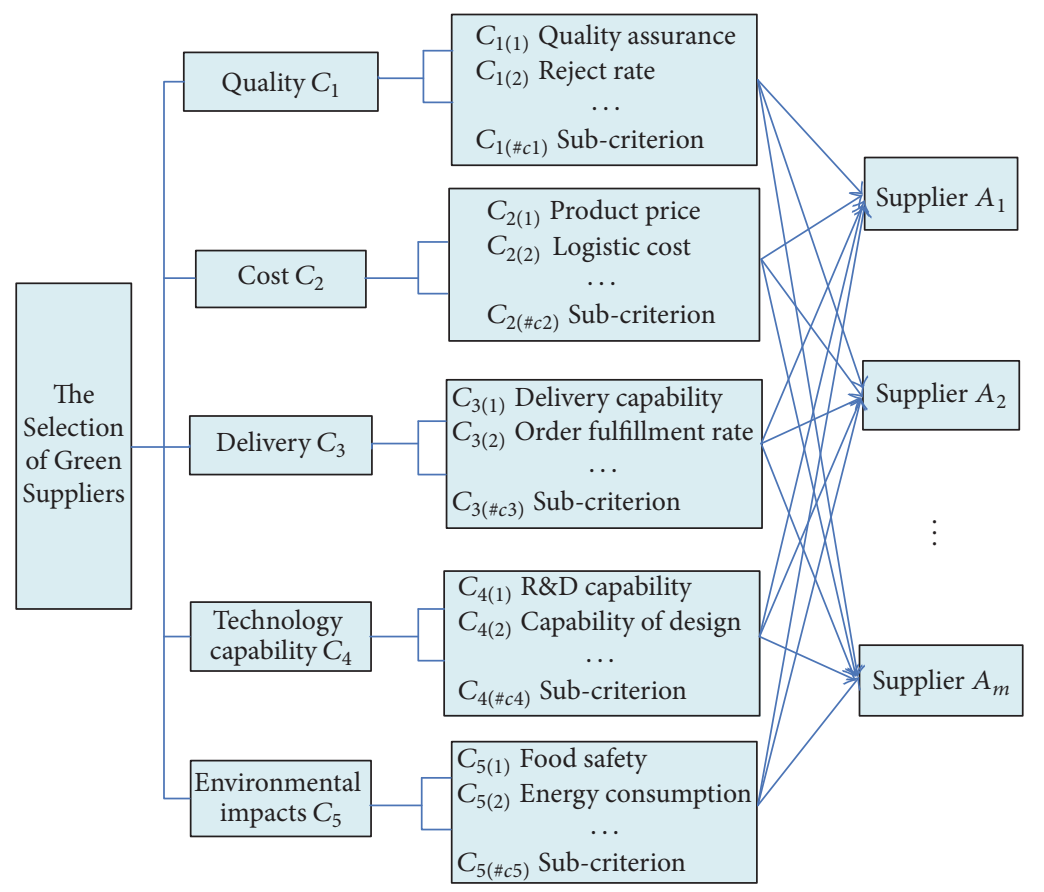

FIgURE 3: The assessed framework of green suppliers in food supply chain.

3.2. The Developed Technique. To solve the aforementioned decision making issue under FLE environment, in the following we first employ the HTrF numbers to represent the semantics of these FLEs and propose a novel closeness degree-based HTrF MCDM approach. The proposed method is based on the principle that the optimal green supplier should have the shortest distance from the PIS and the farthest distance from the NIS. Next, the key issue is to identify HTrF ideal solutions and to calculate the closeness of each solution to the ideal one.

Firstly, we employ HTrF numbers to capture and model the semantics of all decision data represented by FLEs. Namely, in this study each element $\mathrm{fl}_{i j(k)}(i \in\{1,2, \ldots, m\}$, $\left.j \in\{1,2,3,4,5\}, k \in\left\{1,2, \ldots, \# C_{j}\right\}\right)$ in the linguistic decision matrix $\mathrm{fl}$ is represented mathematically by the HTrF number $\widetilde{h}_{i j(k)}=\left\{T\left(a_{i j(k)}^{f}, b_{i j(k)}^{f}, c_{i j(k)}^{f}, d_{i j(k)}^{f}\right) \mid f=1,2, \ldots, \# \widetilde{h}_{i j(k)}\right\}$. Then, using the comparison method of HTrF numbers, the HTrF PIS $\left(\widetilde{h}_{j(k)}\right)^{+}$is identified by the following formula:

$$
\begin{aligned}
\left(\widetilde{h}_{j(k)}\right)^{+}=\max _{i=1}^{m} f\left(\widetilde{h}_{i j(k)}\right), & \\
& k=1,2, \ldots, \# C_{j}, j=1,2,3,4,5,
\end{aligned}
$$

where $f\left(\widetilde{h}_{i j(k)}\right)=\left(1 / 6 \# \widetilde{h}_{i j(k)}\right) \sum_{f=1}^{\# \tilde{h}_{i j(k)}}\left(6-a_{i j(k)}^{f}-2 b_{i j(k)}^{f}-2 c_{i j(k)}^{f}-\right.$ $\left.d_{i j(k)}^{f}\right)$.

The HTrF PISs for this kind of selection issue of suppliers in food supply chain can be obtained as

$$
A^{+}=\left(\begin{array}{cccc}
\left(\widetilde{h}_{1(1)}\right)^{+} & \left(\widetilde{h}_{1(2)}\right)^{+} & \ldots & \left(\widetilde{h}_{1(\# c 1)}\right)^{+} \\
\left(\widetilde{h}_{2(1)}\right)^{+} & \left(\widetilde{h}_{2(2)}\right)^{+} & \ldots & \left(\widetilde{h}_{2(\# c)}\right)^{+} \\
\left(\widetilde{h}_{3(1)}\right)^{+} & \left(\widetilde{h}_{3(2)}\right)^{+} & \ldots & \left(\widetilde{h}_{3(\# c)}\right)^{+} \\
\left(\widetilde{h}_{4(1)}\right)^{+} & \left(\widetilde{h}_{4(2)}\right)^{+} & \ldots & \left(\widetilde{h}_{4(\# c c)}\right)^{+} \\
\left(\widetilde{h}_{5(1)}\right)^{+} & \left(\widetilde{h}_{5(2)}\right)^{+} & \ldots & \left(\widetilde{h}_{5(\# c)}\right)^{+}
\end{array}\right) .
$$

In real-life evaluation and selection process, there usually does not exist HTrF PIS $A^{+}$. That is to say, HTrF PIS $A^{+}$is not the feasible solution; that is, $A^{+} \notin \mathbf{A}$. Otherwise, the $\mathrm{HTrF}$ PIS $A^{+}$which is the best for all criteria is the optimal solution of this selection issue of suppliers, and the decision making process is finished.

Analogously, the HTrF NIS $\left(\widetilde{h}_{j(k)}\right)^{-}$is identified by the following formula:

$$
\begin{aligned}
\left(\widetilde{h}_{j(k)}\right)^{-}=\min _{i=1}^{m} f\left(\widetilde{h}_{i j(k)}\right), & \\
& \quad k=1,2, \ldots, \# C_{j}, j=1,2,3,4,5 .
\end{aligned}
$$

Therefore, the HTrF NISs for this kind of the supplier selection problem in food supply chain can be represented by

$$
A^{-}=\left(\begin{array}{cccc}
\left(\widetilde{h}_{1(1)}\right)^{-} & \left(\widetilde{h}_{1(2)}\right)^{-} & \ldots & \left(\widetilde{h}_{1(\# c 1)}\right)^{-} \\
\left(\widetilde{h}_{2(1)}\right)^{-} & \left(\widetilde{h}_{2(2)}\right)^{-} & \ldots & \left(\widetilde{h}_{2(\# c 2)}\right)^{-} \\
\left(\widetilde{h}_{3(1)}\right)^{-} & \left(\widetilde{h}_{3(2)}\right)^{-} & \ldots & \left(\widetilde{h}_{3(\# c)}\right)^{-} \\
\left(\widetilde{h}_{4(1)}\right)^{-} & \left(\widetilde{h}_{4(2)}\right)^{-} & \ldots & \left(\widetilde{h}_{4(\# c 4)}\right)^{-} \\
\left(\widetilde{h}_{5(1)}\right)^{-} & \left(\widetilde{h}_{5(2)}\right)^{-} & \cdots & \left(\widetilde{h}_{5(\# c 5)}\right)^{-}
\end{array}\right) .
$$

It is noted that HTrF NIS $A^{-}$is also not the feasible solution; that is, $A^{-} \notin$ A. Otherwise, HTrF NIS $A^{-}$which 
is the worst for all criteria should be deleted directly in the MCDM process.

Considering in the aforementioned evaluation problem the weights of the main-criteria and subcriteria are all provided by FLEs; we need to obtain the defuzzification weight values of the main-criteria and subcriteria before calculating the distances between suppliers and HTrF PISs. Based on the concept of the HTrF signed distance, the normalized values of the subcriteria weights $w\left(C_{j(k)}\right)$ are calculated by the following formula:

$$
\bar{f}\left(w\left(C_{j(k)}\right)\right)=\frac{1-f\left(w\left(C_{j k}\right)\right)}{\sum_{k=1}^{\# c_{j}}\left(1-f\left(w\left(C_{j k}\right)\right)\right)},
$$

where $w\left(C_{j k}\right)=\left\{T\left(a_{w\left(C_{j k}\right)}^{f}, b_{w\left(C_{j k}\right)}^{f}, c_{w\left(C_{j k}\right)}^{f}, d_{w\left(C_{j k}\right)}^{f}\right) \mid f=\right.$ $\left.1,2, \ldots, \# w\left(C_{j k}\right)\right\}$ is a $\operatorname{HTrF}$ value and $f\left(w\left(C_{j k}\right)\right)=$ $\left(1 / 6 \# w\left(C_{j k}\right)\right) \sum_{f=1}^{\# w\left(C_{j k}\right)}\left(6-a_{w\left(C_{j k}\right)}^{f}-2 b_{w\left(C_{j k}\right)}^{f}-2 c_{w\left(C_{j k}\right)}^{f}-d_{w\left(C_{j k}\right)}^{f}\right)$.

Analogously, the normalized defuzzification values of the main-criteria weights $w\left(C_{j}\right)$ are calculated as follows:

$$
\bar{f}\left(w\left(C_{j}\right)\right)=\frac{1-f\left(w\left(C_{j}\right)\right)}{\sum_{j=1}^{4}\left(1-f\left(w\left(C_{j}\right)\right)\right)},
$$

where $w\left(C_{j}\right)$ denoted by $w\left(C_{j}\right)=\left\{T\left(a_{w\left(C_{j}\right)}^{f}, b_{w\left(C_{j}\right)}^{f}, c_{w\left(C_{j}\right)}^{f}\right.\right.$, $\left.\left.d_{w\left(C_{j}\right)}^{f}\right) \quad \mid f=1,2, \ldots, \# w\left(C_{j}\right)\right\}$ is a HTrF number and $f\left(w\left(C_{j}\right)\right)=\left(1 / 6 \# w\left(C_{j}\right)\right) \sum_{f=1}^{\# w\left(C_{j}\right)}\left(6-a_{w\left(C_{j}\right)}^{f}-2 b_{w\left(C_{j}\right)}^{f}-2 c_{w\left(C_{j}\right)}^{f}-\right.$ $\left.d_{w\left(C_{j}\right)}^{f}\right)$.

Thus, the overall weight $\Phi_{j k}$ of the subcriterion $C_{j(k)}$ can be obtained by using the following formula:

$$
{\varpi_{j k}}=\bar{f}\left(w\left(C_{j}\right)\right) \otimes\left(\begin{array}{c}
\bar{f}\left(w\left(C_{j(1)}\right)\right) \\
\bar{f}\left(w\left(C_{j(2)}\right)\right) \\
\vdots \\
\bar{f}\left(w\left(C_{j\left(\# C_{j}\right)}\right)\right)
\end{array}\right) .
$$

Next, the distance between the supplier $A_{i}$ and HTrF PIS $A^{+}$can be calculated by using (7) as follows:

$$
\begin{array}{r}
\mathscr{D}\left(A_{i}, A^{+}\right)=\sum_{j=1}^{5} \sum_{k=1}^{\# C_{j}} \varrho_{j(k)}\left(d_{E}\left(\widetilde{h}_{i j(k)}, \widetilde{h}_{j(k)}^{+}\right)\right)^{2} \\
=\sum_{j=1}^{5} \sum_{k=1}^{\# C_{j}}\left(\varrho_{j(k)} \times \frac{1}{6 \# \widetilde{h}}\left(\sum_{f=1}^{\# \widetilde{h}}\left(\left(a_{i j k}^{f}-a_{j k}^{f+}\right)^{2}+2\left(b_{i j k}^{f}-b_{j k}^{f+}\right)^{2}+2\left(c_{i j k}^{f}-c_{j k}^{f+}\right)^{2}+\left(d_{i j k}^{f}-d_{j k}^{f+}\right)^{2}\right)\right)\right), \\
i=1,2, \ldots, m .
\end{array}
$$

In practice, the smaller $\mathscr{D}\left(A_{i}, A^{+}\right)$the better the green supplier $A_{i}$, and let

$$
\mathscr{D}_{\min }\left(A_{i}, A^{+}\right)=\min _{1 \leq i \leq m} \mathscr{D}\left(A_{i}, A^{+}\right) .
$$

However, the green supplier with the closest distance to HTrF PIS cannot guarantee that it is the farthest from
HTrF NIS. To make sure that the optimal solution should have the shortest distance from HTrF PIS and the farthest distance from HTrF NIS, simultaneously, we next calculate the distance between the green supplier $A_{i}$ and HTrF NIS $A^{-}$ by employing the following equation:

$$
\begin{array}{r}
\mathscr{D}\left(A_{i}, A^{-}\right)=\sum_{j=1}^{5} \sum_{k=1}^{\# C_{j}} \varrho_{j(k)}\left(d_{E}\left(\widetilde{h}_{i j(k)}, \widetilde{h}_{j(k)}^{-}\right)\right)^{2} \\
=\sum_{j=1}^{5} \sum_{k=1}^{\# C_{j}}\left(\omega_{j(k)} \times \frac{1}{6 \# \tilde{h}}\left(\sum_{f=1}^{\# \widetilde{h}}\left(\left(a_{i j k}^{f}-a_{j k}^{f-}\right)^{2}+2\left(b_{i j k}^{f}-b_{j k}^{f-}\right)^{2}+2\left(c_{i j k}^{f}-c_{j k}^{f-}\right)^{2}+\left(d_{i j k}^{f}-d_{j k}^{f-}\right)^{2}\right)\right)\right), \\
i=1,2, \ldots, m .
\end{array}
$$

Usually, the bigger $\mathscr{D}\left(A_{i}, A^{-}\right)$, the better green supplier $A_{i}$, and let

$$
\mathscr{D}_{\max }\left(A_{i}, A^{-}\right)=\max _{1 \leq i \leq m} \mathscr{D}\left(A_{i}, A^{-}\right) .
$$

According to the study of Hadi-Vencheh and Mirjaberi [28], the relative closeness degree of the supplier $A_{i}$ is calculated as the following form: 
TABLE 1: The description of the subcriteria and five main-criteria [1] and their weight values.

\begin{tabular}{|c|c|c|c|}
\hline Main-criteria & Weights of main-criteria & Subcriteria & Weights of subcriteria \\
\hline \multirow{2}{*}{$C_{1}$ Quality } & \multirow{2}{*}{$H$} & $C_{1(1)}$ Quality assurance & $M H$ \\
\hline & & $C_{1(2)}$ Reject rate & Between $F$ and $H$ \\
\hline \multirow{2}{*}{$C_{2}$ Cost } & \multirow{2}{*}{ MH } & $C_{2(1)}$ Product price & $H$ \\
\hline & & $C_{2(2)}$ Logistic cost & MH \\
\hline \multirow{2}{*}{$C_{3}$ Delivery } & \multirow{2}{*}{ Between $F$ and $H$} & $C_{3(1)}$ Delivery capabilities & $F$ \\
\hline & & $C_{3(2)}$ Order fulfillment rate & Between $L$ and $M L$ \\
\hline \multirow{2}{*}{$C_{4}$ Technology capability } & \multirow{2}{*}{ At least $M H$} & $C_{4(1)} \mathrm{R} \& \mathrm{D}$ capability & $F$ \\
\hline & & $C_{4(2)}$ Capability of design & $M L$ \\
\hline \multirow{7}{*}{$C_{5}$ Environmental impacts } & \multirow{7}{*}{ Between $F$ and $M H$} & $C_{5(1)}$ Food safety & At least $M H$ \\
\hline & & $C_{5(2)}$ Energy consumption & MH \\
\hline & & $C_{5(3)}$ Solid waste generation & Between $F$ and $H$ \\
\hline & & $C_{5(4)}$ Air emission & $H$ \\
\hline & & $C_{5(5)}$ Waste water treatment & Between $F$ and $M H$ \\
\hline & & $C_{5(6)}$ Environmental management system & $M H$ \\
\hline & & $C_{5(7)}$ Corporate social responsibility & $H$ \\
\hline
\end{tabular}

$$
\mathcal{\vartheta}\left(A_{i}\right)=\frac{\mathscr{D}\left(A_{i}, A^{-}\right)}{\mathscr{D}_{\max }\left(A_{i}, A^{-}\right)}-\frac{\mathscr{D}\left(A_{i}, A^{+}\right)}{\mathscr{D}_{\min }\left(A_{i}, A^{+}\right)} .
$$

It is easily observed that $\vartheta\left(A_{i}\right)$ is used to measure the extent to which the green supplier $A_{i}$ closes to HTrF PIS $A^{+}$ and is far away from HTrF NIS $A^{-}$, synchronously, which is also called the revised closeness index in [19]. It can be easily seen that $\vartheta\left(A_{i}\right) \leq 0(i=1,2, \ldots, m)$ and the bigger the value of $\vartheta\left(A_{i}\right)$, the better the green supplier $A_{i}$. If there exists one green supplier $A^{*}$ satisfying the conditions that $\mathscr{D}\left(A^{*}, A^{-}\right)=\mathscr{D}_{\max }\left(A_{i}, A^{-}\right)$and $\mathscr{D}\left(A^{*}, A^{+}\right)=\mathscr{D}_{\min }\left(A_{i}, A^{+}\right)$, synchronously, then $\vartheta\left(A^{*}\right)=0$. Obviously, the green supplier $A^{*}$ is the best choice for the food company; this compromise solution is closest to HTrF PIS $A^{+}$and farthest away from $\mathrm{HTrF}$ NIS $A^{-}$, synchronously.

Remark 6. According to the classical TOPSIS approach, the relative closeness values defined in (22) of objects are usually used to determine the ranking of these objects:

$$
\wp\left(A_{i}\right)=\frac{\mathscr{D}\left(A_{i}, A^{-}\right)}{\mathscr{D}\left(A_{i}, A^{+}\right)+\mathscr{D}\left(A_{i}, A^{-}\right)} .
$$

However, some academics [28] recently pointed out that the optimal solution identified by the relative closeness fails to guarantee that it has the shortest distance from the PIS and the farthest distance from the NIS, synchronously. Obviously, the revised closeness index is more reasonable because it can well overcome this drawback.

To facilitate the decision making processes in dealing with actual MCDM issues, the algorithm of the proposed HTrF MCDM technique is summarized in Figure 4.

\section{A Case Study for the Evaluation of Green Suppliers in Food Supply Chain}

This section discusses how to employ the developed HTrF MCDM technique to select a best suitable supplier for the food company in food supply chain.

4.1. Application of the Developed Technique. We here consider one green supplier selection problem in food supply chain which includes four potential green suppliers $\left\{A_{1}, A_{2}, A_{3}, A_{4}\right\}$. These four qualified green suppliers have the capability to fulfill the food companies purchasing requirement. An expert panel that has vast knowledge and experience in food supply chain and environmental management systems was formed to conduct the assessment involved with four potential suppliers. Through the expert panel discussion, five assessed main-criteria are first determined and shown in Table 1, and then different subcriteria under these five main-criteria are also identified in Table 1.

To increase the accuracy of the assignment of criteria weights and criteria values, in this study the evaluator is allowed to use linguistic terms or FLEs to express their opinions over these four suppliers. Then, based on the sevenpoint rating scale-based linguistic rating system introduced in Figure 1, these four qualified green suppliers are evaluated with respect to the detailed subcriteria and the assessments are also represented by FLEs or linguistic terms which are listed in in Table 2. Accordingly, the weights of main-criteria and subcriteria provided by the evaluator are also represented by FLEs, which are listed in Table 1.

In the following, the HTrF MCDM approach discussed in Section 3 is employed to assist the food firm to identify the most appropriate suppliers. Firstly, based on the linguistic rating system based on $\operatorname{TrFN}$ data given in Figure 1, all linguistic decision data in Table 2 are converted into the 


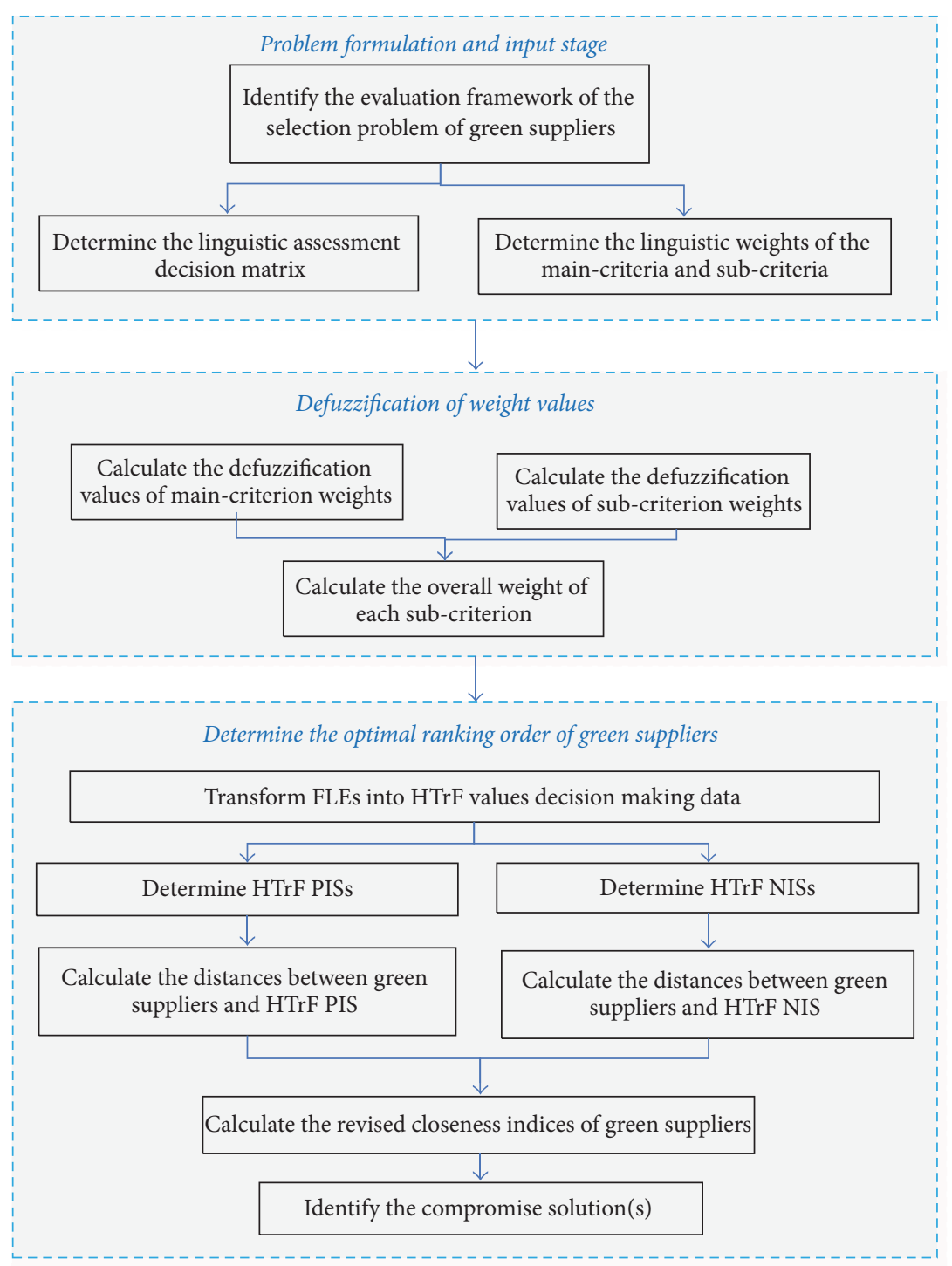

Figure 4: The diagram of the decision processes for the HTrF MCDM technique.

HTrF decision data. Then, the normalized HTrF evaluated data of green suppliers with respect to each subcriterion under the main-criterion are identified according to the extended regulations presented by Zhang et al. [17] (introduced in Section 2) and are listed in Table 3. Then, we utilize (10) and (12) to determine HTrF PIS $A^{+}$and HTrF NIS $A^{-}$, respectively, and the obtained results are listed in Table 4.

Furthermore, the normalized criteria weights are obtained by using (14) and (15), which are illustrated in Table 5. Thus, we can use (16) to calculate the overall criteria weights, and the calculated results are listed in Table 5.

Afterwards, the distances between the supplier $A_{i}$ and HTrF PIS $A^{+}$are computed by (17), and the distances between the supplier $A_{i}$ and HTrF NIS $A^{-}$are obtained by (19), respectively. These calculated results are provided in Table 6. Meanwhile, the revised closeness degree $\vartheta\left(A_{i}\right)$ of the supplier $A_{i}$ is determined by utilizing (21), which is also shown in
Table 6. According to the value of $\vartheta\left(A_{i}\right)$, the ranking of green suppliers is identified in Table 6.

It is easy to see from Table 6 that the ranking of suppliers is $A_{4}>A_{3}>A_{2}>A_{1}$ and thus the best choice for the food firm is to cooperate with the green supplier $A_{4}$. It is noted that our developed technique can not only provide a simple and efficient decision support tool but also enable the managers of the food company to better understand the complete evaluation and decision process.

4.2. Comparative Analysis and Discussions. One of the most important advantages of the developed HTrF MCDM method is to allow the assessors to employ FLEs to express their opinions on the criteria values and the criteria weights. To demonstrate the advantage on criteria weights, in the following three different weight vectors $(M-1, M-2$, and $M$ 3 ) are provided and illustrated in Figure 5. It is noted that the weight vector under Case $M-1$ is obtained based on FLEs 
TABLE 2: The FLE evaluation results of green suppliers in food supply chain.

\begin{tabular}{|c|c|c|c|c|}
\hline \multirow{2}{*}{ Subcriteria } & \multicolumn{4}{|c|}{ Green suppliers } \\
\hline & $A_{1}$ & $A_{2}$ & $A_{3}$ & $A_{4}$ \\
\hline$C_{1(1)}$ & Between $M G$ and $G$ & At least $G$ & $G$ & $M G$ \\
\hline$C_{1(2)}$ & $M G$ & At most $M P$ & $M P$ & Between MP and F \\
\hline$C_{2(1)}$ & $M G$ & Between $M G$ and $G$ & At least $M G$ & $G$ \\
\hline$C_{2(2)}$ & $M P$ & $M G$ & Between $P$ and $M P$ & $M G$ \\
\hline$C_{3(1)}$ & Between $F$ and $G$ & $G$ & $G$ & Between $M G$ and $G$ \\
\hline$C_{3(2)}$ & Between MP and F & $F$ & $P$ & Between $P$ and $M P$ \\
\hline$C_{4(1)}$ & Between $P$ and $M P$ & Between MP and F & $F$ & $M G$ \\
\hline$C_{4(2)}$ & G & $M G$ & At least $G$ & $V G$ \\
\hline$C_{5(1)}$ & $F$ & $M P$ & $P$ & $M P$ \\
\hline$C_{5(2)}$ & $M P$ & At most $P$ & $F$ & Between $P$ and $F$ \\
\hline$C_{5(3)}$ & $M P$ & $F$ & At most $M P$ & Between $P$ and $M P$ \\
\hline$C_{5(4)}$ & Between MP and F & Between $P$ and $M P$ & $F$ & $M G$ \\
\hline$C_{5(5)}$ & $M G$ & At least $M G$ & $M G$ & At least $G$ \\
\hline$C_{5(6)}$ & $M P$ & At least MP & $M P$ & $F$ \\
\hline$C_{5(7)}$ & At most $P$ & F & Between $F$ and $G$ & $M P$ \\
\hline
\end{tabular}

TABLE 3: The normalized HTrF evaluation results of green suppliers.

\begin{tabular}{|c|c|c|c|c|}
\hline \multirow{2}{*}{ Criteria } & \multicolumn{4}{|c|}{ Green suppliers } \\
\hline & $A_{1}$ & $A_{2}$ & $A_{3}$ & $A_{4}$ \\
\hline$C_{1(1)}$ & $\left\{\alpha_{5}, \alpha_{5}, \alpha_{6}\right\}$ & $\left\{\alpha_{6}, \alpha_{6}, \alpha_{7}\right\}$ & $\left\{\alpha_{6}, \alpha_{6}, \alpha_{6}\right\}$ & $\left\{\alpha_{5}, \alpha_{5}, \alpha_{5}\right\}$ \\
\hline$C_{1(2)}$ & $\left\{\alpha_{5}, \alpha_{5}, \alpha_{5}\right\}$ & $\left\{\alpha_{1}, \alpha_{2}, \alpha_{3}\right\}$ & $\left\{\alpha_{3}, \alpha_{3}, \alpha_{3}\right\}$ & $\left\{\alpha_{3}, \alpha_{3}, \alpha_{4}\right\}$ \\
\hline$C_{2(1)}$ & $\left\{\alpha_{5}, \alpha_{5}, \alpha_{5}\right\}$ & $\left\{\alpha_{5}, \alpha_{5}, \alpha_{6}\right\}$ & $\left\{\alpha_{5}, \alpha_{6}, \alpha_{7}\right\}$ & $\left\{\alpha_{6}, \alpha_{6}, \alpha_{6}\right\}$ \\
\hline$C_{2(2)}$ & $\left\{\alpha_{3}, \alpha_{3}, \alpha_{3}\right\}$ & $\left\{\alpha_{5}, \alpha_{5}, \alpha_{5}\right\}$ & $\left\{\alpha_{2}, \alpha_{2}, \alpha_{3}\right\}$ & $\left\{\alpha_{5}, \alpha_{5}, \alpha_{5}\right\}$ \\
\hline$C_{3(1)}$ & $\left\{\alpha_{4}, \alpha_{5}, \alpha_{6}\right\}$ & $\left\{\alpha_{6}, \alpha_{6}, \alpha_{6}\right\}$ & $\left\{\alpha_{6}, \alpha_{6}, \alpha_{6}\right\}$ & $\left\{\alpha_{5}, \alpha_{5}, \alpha_{6}\right\}$ \\
\hline$C_{3(2)}$ & $\left\{\alpha_{3}, \alpha_{3}, \alpha_{4}\right\}$ & $\left\{\alpha_{4}, \alpha_{4}, \alpha_{4}\right\}$ & $\left\{\alpha_{2}, \alpha_{2}, \alpha_{2}\right\}$ & $\left\{\alpha_{2}, \alpha_{2}, \alpha_{3}\right\}$ \\
\hline$C_{4(1)}$ & $\left\{\alpha_{2}, \alpha_{2}, \alpha_{3}\right\}$ & $\left\{\alpha_{3}, \alpha_{3}, \alpha_{4}\right\}$ & $\left\{\alpha_{4}, \alpha_{4}, \alpha_{4}\right\}$ & $\left\{\alpha_{5}, \alpha_{5}, \alpha_{5}\right\}$ \\
\hline$C_{4(2)}$ & $\left\{\alpha_{6}, \alpha_{6}, \alpha_{6}\right\}$ & $\left\{\alpha_{5}, \alpha_{5}, \alpha_{5}\right\}$ & $\left\{\alpha_{6}, \alpha_{6}, \alpha_{7}\right\}$ & $\left\{\alpha_{7}, \alpha_{7}, \alpha_{7}\right\}$ \\
\hline$C_{5(1)}$ & $\left\{\alpha_{4}, \alpha_{4}, \alpha_{4}\right\}$ & $\left\{\alpha_{3}, \alpha_{3}, \alpha_{3}\right\}$ & $\left\{\alpha_{2}, \alpha_{2}, \alpha_{2}\right\}$ & $\left\{\alpha_{3}, \alpha_{3}, \alpha_{3}\right\}$ \\
\hline$C_{5(2)}$ & $\left\{\alpha_{3}, \alpha_{3}, \alpha_{3}\right\}$ & $\left\{\alpha_{1}, \alpha_{1}, \alpha_{2}\right\}$ & $\left\{\alpha_{4}, \alpha_{4}, \alpha_{4}\right\}$ & $\left\{\alpha_{3}, \alpha_{3}, \alpha_{4}\right\}$ \\
\hline$C_{5(3)}$ & $\left\{\alpha_{3}, \alpha_{3}, \alpha_{3}\right\}$ & $\left\{\alpha_{4}, \alpha_{4}, \alpha_{4}\right\}$ & $\left\{\alpha_{1}, \alpha_{2}, \alpha_{3}\right\}$ & $\left\{\alpha_{2}, \alpha_{2}, \alpha_{3}\right\}$ \\
\hline$C_{5(4)}$ & $\left\{\alpha_{3}, \alpha_{3}, \alpha_{4}\right\}$ & $\left\{\alpha_{2}, \alpha_{2}, \alpha_{3}\right\}$ & $\left\{\alpha_{4}, \alpha_{4}, \alpha_{4}\right\}$ & $\left\{\alpha_{5}, \alpha_{5}, \alpha_{5}\right\}$ \\
\hline$C_{5(5)}$ & $\left\{\alpha_{5}, \alpha_{5}, \alpha_{5}\right\}$ & $\left\{\alpha_{5}, \alpha_{6}, \alpha_{7}\right\}$ & $\left\{\alpha_{5}, \alpha_{5}, \alpha_{5}\right\}$ & $\left\{\alpha_{6}, \alpha_{6}, \alpha_{7}\right\}$ \\
\hline$C_{5(6)}$ & $\left\{\alpha_{3}, \alpha_{3}, \alpha_{3}\right\}$ & $\left\{\alpha_{1}, \alpha_{2}, \alpha_{3}\right\}$ & $\left\{\alpha_{3}, \alpha_{3}, \alpha_{3}\right\}$ & $\left\{\alpha_{4}, \alpha_{4}, \alpha_{4}\right\}$ \\
\hline$C_{5(7)}$ & $\left\{\alpha_{1}, \alpha_{1}, \alpha_{2}\right\}$ & $\left\{\alpha_{4}, \alpha_{4}, \alpha_{4}\right\}$ & $\left\{\alpha_{4}, \alpha_{5}, \alpha_{6}\right\}$ & $\left\{\alpha_{3}, \alpha_{3}, \alpha_{3}\right\}$ \\
\hline
\end{tabular}

Note. $\alpha_{1}=T(0.0,0.0,0.1,0.2), \alpha_{2}=T(0.1,0.2,0.2,0.3), \alpha_{3}=T(0.2,0.3,0.4,0.5), \alpha_{4}=T(0.4,0.5,0.5,0.6), \alpha_{5}=T(0.5,0.6,0.7,0.8), \alpha_{6}=T(0.7,0.8,0.8,0.9)$, $\alpha_{7}=T(0.8,0.9,1.0,1.0)$.

opinions and has been discussed in the developed technique, while the weight vectors under Case $M-2$ and Case $M-3$ are given by the assessors subjectively. It is easily observed that more weights are given in environmental criteria in Case $M$ 3 and more weights are given on technology capability and delivery criteria in Case $M-2$.

With three different weight vectors, using the developed technique the revised closeness degrees of these four green suppliers are obtained in Figure 6 and the correspondingly optimal ranking orders of these four suppliers are determined in Figure 6. It is easily observed from Figure 6 that the best choice for the food company is to cooperate with the supplier $A_{4}$. Nevertheless, the ranking orders among the green suppliers $\left\{A_{1}, A_{2}, A_{3}\right\}$ are totally different based on these three cases. The main reason is that the weight distributions among these fifteen evaluated criteria under 


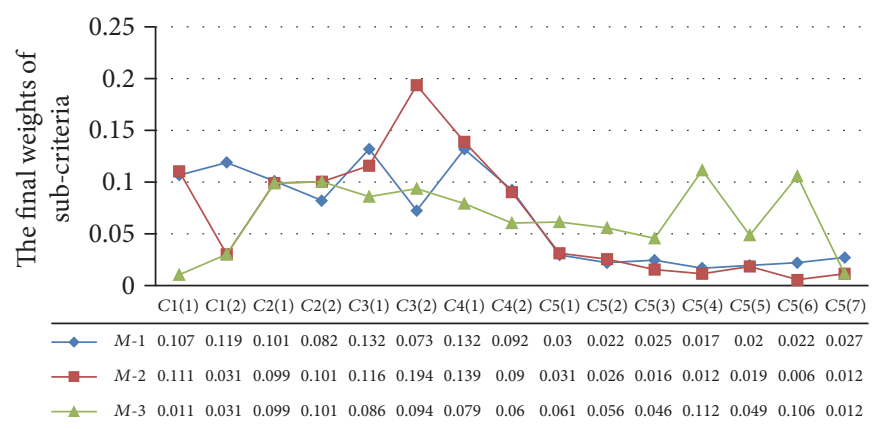

FIGURE 5: The weight values of evaluation criteria based on different situations.

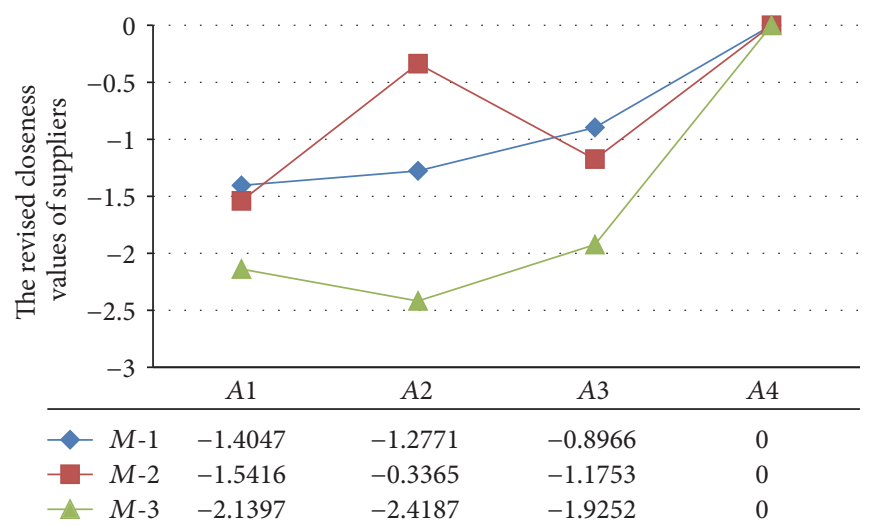

Figure 6: The revised closeness values and the rankings of suppliers with different criteria weights.

TABLE 4: HTrF PISs and HTrF NISs.

\begin{tabular}{lll}
\hline \multirow{2}{*}{ Subcriteria } & \multicolumn{2}{c}{ HTrF deal solutions } \\
& HTrF PISs & HTrF NISs \\
\hline$C_{1(1)}$ & $\left\{\alpha_{6}, \alpha_{6}, \alpha_{7}\right\}$ & $\left\{\alpha_{5}, \alpha_{5}, \alpha_{5}\right\}$ \\
$C_{1(2)}$ & $\left\{\alpha_{5}, \alpha_{5}, \alpha_{5}\right\}$ & $\left\{\alpha_{1}, \alpha_{2}, \alpha_{3}\right\}$ \\
$C_{2(1)}$ & $\left\{\alpha_{5}, \alpha_{6}, \alpha_{7}\right\}$ & $\left\{\alpha_{5}, \alpha_{5}, \alpha_{5}\right\}$ \\
$C_{2(2)}$ & $\left\{\alpha_{5}, \alpha_{5}, \alpha_{5}\right\}$ & $\left\{\alpha_{2}, \alpha_{2}, \alpha_{3}\right\}$ \\
$C_{3(1)}$ & $\left\{\alpha_{6}, \alpha_{6}, \alpha_{6}\right\}$ & $\left\{\alpha_{4}, \alpha_{5}, \alpha_{6}\right\}$ \\
$C_{3(2)}$ & $\left\{\alpha_{4}, \alpha_{4}, \alpha_{4}\right\}$ & $\left\{\alpha_{2}, \alpha_{2}, \alpha_{2}\right\}$ \\
$C_{4(1)}$ & $\left\{\alpha_{5}, \alpha_{5}, \alpha_{5}\right\}$ & $\left\{\alpha_{2}, \alpha_{2}, \alpha_{2}\right\}$ \\
$C_{4(2)}$ & $\left\{\alpha_{7}, \alpha_{7}, \alpha_{7}\right\}$ & $\left\{\alpha_{5}, \alpha_{5}, \alpha_{5}\right\}$ \\
$C_{5(1)}$ & $\left\{\alpha_{4}, \alpha_{4}, \alpha_{4}\right\}$ & $\left\{\alpha_{2}, \alpha_{2}, \alpha_{2}\right\}$ \\
$C_{5(2)}$ & $\left\{\alpha_{4}, \alpha_{4}, \alpha_{4}\right\}$ & $\left\{\alpha_{1}, \alpha_{1}, \alpha_{2}\right\}$ \\
$C_{5(3)}$ & $\left\{\alpha_{4}, \alpha_{4}, \alpha_{4}\right\}$ & $\left\{\alpha_{1}, \alpha_{2}, \alpha_{3}\right\}$ \\
$C_{5(4)}$ & $\left\{\alpha_{5}, \alpha_{5}, \alpha_{5}\right\}$ & $\left\{\alpha_{2}, \alpha_{2}, \alpha_{3}\right\}$ \\
$C_{5(5)}$ & $\left\{\alpha_{6}, \alpha_{6}, \alpha_{7}\right\}$ & $\left\{\alpha_{5}, \alpha_{5}, \alpha_{5}\right\}$ \\
$C_{5(6)}$ & $\left\{\alpha_{4}, \alpha_{4}, \alpha_{4}\right\}$ & $\left\{\alpha_{1}, \alpha_{2}, \alpha_{3}\right\}$ \\
$C_{5(7)}$ & $\left\{\alpha_{4}, \alpha_{5}, \alpha_{6}\right\}$ & $\left\{\alpha_{1}, \alpha_{1}, \alpha_{2}\right\}$ \\
\hline
\end{tabular}

these three cases are completely different. Our developed approach allows the assessors to utilize the FLEs to present their vague opinions, which greatly increases the accuracy of the assignment of criteria weights in evaluating processes.

In addition, Beg and Rashid [22] recently developed hesitant fuzzy LTSs TOPSIS method. Zhang et al. [17] proposed HTrF QUALIFLEX technique to handle the MCDM issues with hierarchical structure in which the decision data are represented by FLEs base on HTrF values. To this end, we conduct a comparison analysis among the HTrF MCDM technique, the hesitant fuzzy linguistic TOPSIS technique, and the HTrF QUALIFLEX technique in Table 7.

According to the Table 7 , it is easily observed that the proposed HTrF MCDM technique employed FLEs to express the criteria values and the criteria weights in the evaluation processes, while hesitant fuzzy linguistic TOPSIS [22] uses hesitant fuzzy LTSs to express the criteria values and the criteria weights. Meanwhile, in the developed technique, the optimal supplier is identified based on the revised closeness degrees of green suppliers, which can make sure that the solution has the shortest distance from the HTrF PIS and the farthest distance from the HTrF NIS, simultaneously. But hesitant fuzzy linguistic TOPSIS [22] fail to achieve this goal. On the other hand, although the HTrF QUALIFLEX [17] 
TABLE 5: The defuzzification values of the criteria weights as well as the overall weights.

\begin{tabular}{|c|c|c|c|c|}
\hline Main-criteria & $\begin{array}{c}\text { Defuzzification values of } \\
\text { main-criteria weights }\end{array}$ & Subcriteria & $\begin{array}{c}\text { Defuzzification values of } \\
\text { subcriteria weights }\end{array}$ & The overall weights \\
\hline \multirow{2}{*}{$C_{1}$} & \multirow{2}{*}{0.2257} & $C_{1(1)}$ & 0.4727 & 0.1067 \\
\hline & & $C_{1(2)}$ & 0.5273 & 0.1190 \\
\hline \multirow{2}{*}{$C_{2}$} & \multirow{2}{*}{0.1834} & $C_{2(1)}$ & 0.5517 & 0.1012 \\
\hline & & $C_{2(2)}$ & 0.4483 & 0.0822 \\
\hline \multirow{2}{*}{$C_{3}$} & \multirow{2}{*}{0.2045} & $C_{3(1)}$ & 0.6452 & 0.1320 \\
\hline & & $C_{3(2)}$ & 0.3548 & 0.0726 \\
\hline \multirow{2}{*}{$C_{4}$} & \multirow{2}{*}{0.2241} & $C_{4(1)}$ & 0.5882 & 0.1318 \\
\hline & & $C_{4(2)}$ & 0.4118 & 0.0923 \\
\hline \multirow{7}{*}{$C_{5}$} & \multirow{7}{*}{0.1622} & $C_{5(1)}$ & 0.1818 & 0.0295 \\
\hline & & $C_{5(2)}$ & 0.1364 & 0.0221 \\
\hline & & $C_{5(3)}$ & 0.1521 & 0.0247 \\
\hline & & $C_{5(4)}$ & 0.1049 & 0.0170 \\
\hline & & $C_{5(5)}$ & 0.1206 & 0.0196 \\
\hline & & $C_{5(6)}$ & 0.1364 & 0.0221 \\
\hline & & $C_{5(7)}$ & 0.1678 & 0.0272 \\
\hline
\end{tabular}

TABLE 6: The revised closeness of suppliers and the ranking order of suppliers.

\begin{tabular}{ccccc}
\hline & $\mathscr{D}\left(A_{i}, A^{+}\right)$ & $\mathscr{D}\left(A_{i}, A^{-}\right)$ & $\mathcal{\vartheta}\left(A_{i}\right)$ & Ranking \\
\hline$A_{1}$ & 0.0554 & 0.0404 & -1.4047 & 4 \\
$A_{2}$ & 0.0538 & 0.0452 & -1.2771 & 3 \\
$A_{3}$ & 0.0432 & 0.0450 & -0.8966 & 2 \\
$A_{4}$ & 0.0277 & 0.0677 & 0.0000 & 1 \\
\hline
\end{tabular}

can also deal with the FLE criteria values and the FLE weights of criteria, it requires the tedious computations processes when handling the MCDM issues with a sufficiently large number of alternatives [29], while our proposed HTrF MCDM method exhibits its advantage on dealing with this kind of complex decision making problems.

\section{Conclusions}

The selection of green suppliers is a key activity in food supply chain owing to the fact that low quality and/or delayed delivery caused by suppliers make the food product unsafe or expired. Due to the complexity of real-world environment in evaluating such selection problems, the evaluators prefer to use FLEs for expressing their uncertain opinions. This study has presented a novel closeness degree-based HTrF MCDM approach to adequately evaluate and select the best suitable suppliers in food supply chain under complex environment in which the performances of green suppliers are represented by FLEs. The developed technique is flexible enough to be applied in handling different real-world MCDM problems in other industries involving uncertain qualitative information. The main advantages of our proposed approach are that (1) it allows decision makers/experts to use FLEs to present the uncertain qualitative information on the green suppliers under different evaluation factors, which greatly increases the accuracy of the assignment of criteria weights and criteria values; (2) it presents the optimal solutions which are closest to HTrF PIS and farthest from HTrF NIS, synchronous, which enables the managers to better understand the complete evaluation and decision process. In addition, from the perspective of HTrF theory, this study has also presented a new general $\mathrm{HTrF}$ distance measure and developed a novel defuzzification technique for HTrF numbers.

On the other hand, along with the mass and diversity of decision data and/or the interrelationship among the evaluation criteria, the actual decision making problems become more and more complicated. To overcome these challenges, in the future study we will integrate the clustering algorithms and/or Choquet integral into the developed HTrF MCDM technique.

\section{Conflicts of Interest}

The authors declare that they have no conflicts of interest.

\section{Acknowledgments}

The work was supported by the National Natural Science Foundation of China (nos. 71661010, 71740021), the Major Program of the National Social Science Foundation of China 
TABLE 7: Distinct characteristics of three different MCDM techniques.

\begin{tabular}{|c|c|c|c|c|}
\hline & \multicolumn{4}{|c|}{ The MCDM techniques with different features } \\
\hline & $\begin{array}{c}\text { Types of performance } \\
\text { ratings }\end{array}$ & $\begin{array}{l}\text { Types of criteria } \\
\text { weights }\end{array}$ & Types of ranking methods & Types of MCDM \\
\hline $\begin{array}{l}\text { The proposed HTrF } \\
\text { MCDM technique }\end{array}$ & FLEs/HTrF values & FLEs/HTrF values & $\begin{array}{l}\text { The revised closeness degrees to ideal } \\
\text { solutions-based ranking method }\end{array}$ & Hierarchical MCDM \\
\hline $\begin{array}{l}\text { Hesitant fuzzy linguistic } \\
\text { TOPSIS technique [22] }\end{array}$ & Hesitant fuzzy LTS & Crisp values & $\begin{array}{l}\text { The closeness degrees to ideal } \\
\text { solutions-based ranking method }\end{array}$ & MCDM \\
\hline $\begin{array}{l}\text { HTrF QUALIFLEX } \\
\text { technique [17] }\end{array}$ & FLEs/HTrF values & FLEs/HTrF values & $\begin{array}{l}\text { The concordance/discordance } \\
\text { index-based ranking method }\end{array}$ & Hierarchical MCDM \\
\hline
\end{tabular}

(no. 15ZDC021), the Natural Science Foundation of Jiangxi Province of China (no. 20161BAB211020), and the Technology Project of Education Department of Jiangxi Province of China (no. GJJ160455).

\section{References}

[1] K. Govindan, M. Kadziński, and R. Sivakumar, "Application of a novel promethee-based method for construction of a group compromise ranking to prioritization of green suppliers in food supply chain," Omega, vol. 71, pp. 129-145, 2017.

[2] S. Matos and J. Hall, "Integrating sustainable development in the supply chain: The case of life cycle assessment in oil and gas and agricultural biotechnology," Journal of Operations Management, vol. 25, no. 6, pp. 1083-1102, 2007.

[3] K.-C. Shang, C.-S. Lu, and S. Li, "A taxonomy of green supply chain management capability among electronics-related manufacturing firms in Taiwan," Journal of Environmental Management, vol. 91, no. 5, pp. 1218-1226, 2010.

[4] C. L. Hwang and K. Yoon, Multiple Attribute Decision Making: Methods and Applications, vol. 186, Springer, Berlin, Germany, 1981.

[5] D. Kannan, A. B. Lopes de Sousa Jabbour, and C. J. Chiappetta Jabbour, "Selecting green suppliers based on GSCM practices: using fuzzy TOPSIS applied to a Brazilian electronics company," European Journal of Operational Research, vol. 233, no. 2, pp. 432-447, 2014.

[6] J.-P. Brans, P. Vincke, and B. Mareschal, "How to select and how to rank projects: the PROMETHEE method," European Journal of Operational Research, vol. 24, no. 2, pp. 228-238, 1986.

[7] J.H. P. Paelinck, "Qualiflex: A flexible multiple-criteria method," Economics Letters, vol. 1, no. 3, pp. 193-197, 1978.

[8] X. Zhang, "Multicriteria Pythagorean fuzzy decision analysis: a hierarchical QUALIFLEX approach with the closeness indexbased ranking methods," Information Sciences, vol. 330, pp. 104124, 2016.

[9] F. E. Boran, S. Genç, M. Kurt, and D. Akay, "A multi-criteria intuitionistic fuzzy group decision making for supplier selection with TOPSIS method," Expert Systems with Applications, vol. 36, no. 8, pp. 11363-11368, 2009.

[10] G. Büyüközkan and G. Çifçi, "A novel hybrid MCDM approach based on fuzzy DEMATEL, fuzzy ANP and fuzzy TOPSIS to evaluate green suppliers," Expert Systems with Applications, vol. 39, no. 3, pp. 3000-3011, 2012.

[11] M. Zeydan and C. Çolpan, "A new decision support system for performance measurement using combined fuzzy TOPSIS/ DEA approach," International Journal of Production Research, vol. 47, no. 15, pp. 4327-4349, 2009.
[12] I. Ertuğrul and N. Karakaşoğlu, "Comparison of fuzzy AHP and fuzzy TOPSIS methods for facility location selection," The International Journal of Advanced Manufacturing Technology, vol. 39, no. 7-8, pp. 783-795, 2008.

[13] D. Yong, "Plant location selection based on fuzzy TOPSIS," The International Journal of Advanced Manufacturing Technology, vol. 28, no. 7-8, pp. 839-844, 2006.

[14] A. Kelemenis and D. Askounis, "A new TOPSIS-based multicriteria approach to personnel selection," Expert Systems with Applications, vol. 37, no. 7, pp. 4999-5008, 2010.

[15] Y. Wang and T. M. S. Elhag, "Fuzzy TOPSIS method based on alpha level sets with an application to bridge risk assessment," Expert Systems with Applications, vol. 31, no. 2, pp. 309-319, 2006.

[16] I. Chamodrakas, N. Alexopoulou, and D. Martakos, "Customer evaluation for order acceptance using a novel class of fuzzy methods based on TOPSIS," Expert Systems with Applications, vol. 36, no. 4, pp. 7409-7415, 2009.

[17] X. Zhang, Z. Xu, and M. Liu, "Hesitant trapezoidal fuzzy QUALIFLEX method and its application in the evaluation of green supply chain initiatives," Sustainability, vol. 8, no. 9, article no. 952, 2016.

[18] Z. Xu and X. Zhang, "Hesitant fuzzy multi-attribute decision making based on TOPSIS with incomplete weight information," Knowledge-Based Systems, vol. 52, pp. 53-64, 2013.

[19] X. L. Zhang and Z. S. Xu, "Extension of TOPSIS to multiple criteria decision making with pythagorean fuzzy sets," International Journal of Intelligent Systems, vol. 29, no. 12, pp. 1061-1078, 2014.

[20] J. H. Park, I. Y. Park, Y. C. Kwun, and X. Tan, "Extension of the TOPSIS method for decision making problems under intervalvalued intuitionistic fuzzy environment," Applied Mathematical Modelling: Simulation and Computation for Engineering and Environmental Systems, vol. 35, no. 5, pp. 2544-2556, 2011.

[21] X. L. Zhang and Z. S. Xu, "Soft computing based on maximizing consensus and fuzzy TOPSIS approach to interval-valued intuitionistic fuzzy group decision making," Applied Soft Computing, vol. 26, pp. 42-56, 2015.

[22] I. Beg and T. Rashid, "TOPSIS for hesitant fuzzy linguistic term sets," International Journal of Intelligent Systems, vol. 28, no. 12, pp. 1162-1171, 2013.

[23] M. Xia and Z. Xu, "Hesitant fuzzy information aggregation in decision making," International Journal of Approximate Reasoning, vol. 52, no. 3, pp. 395-407, 2011.

[24] R. R. Yager, "An approach to ordinal decision making," International Journal of Approximate Reasoning, vol. 12, no. 3-4, pp. 237-261, 1995. 
[25] R. M. Rodriguez, L. Martinez, and F. Herrera, "Hesitant fuzzy linguistic term sets for decision making," IEEE Transactions on Fuzzy Systems, vol. 20, no. 1, pp. 109-119, 2012.

[26] L. A. Zadeh, "The concept of a linguistic variable and its application to approximate reasoning-I," Information Sciences, vol. 8, no. 3, pp. 199-249, 1975.

[27] A. H. I. Lee, H. Kang, C. F. Hsu, and H. Hung, "A green supplier selection model for high-tech industry," Expert Systems with Applications, vol. 36, no. 4, pp. 7917-7927, 2009.

[28] A. Hadi-Vencheh and M. Mirjaberi, "Fuzzy inferior ratio method for multiple attribute decision making problems," Information Sciences, vol. 277, pp. 263-272, 2014.

[29] X. Zhang and Z. Xu, "Hesitant fuzzy QUALIFLEX approach with a signed distance-based comparison method for multiple criteria decision analysis," Expert Systems with Applications, vol. 42, no. 2, pp. 873-884, 2015. 


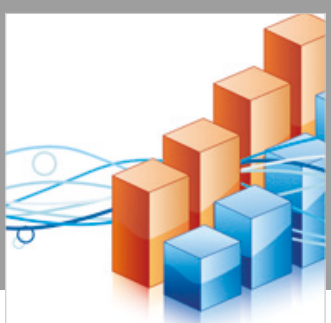

Advances in

Operations Research

\section{-n-m}
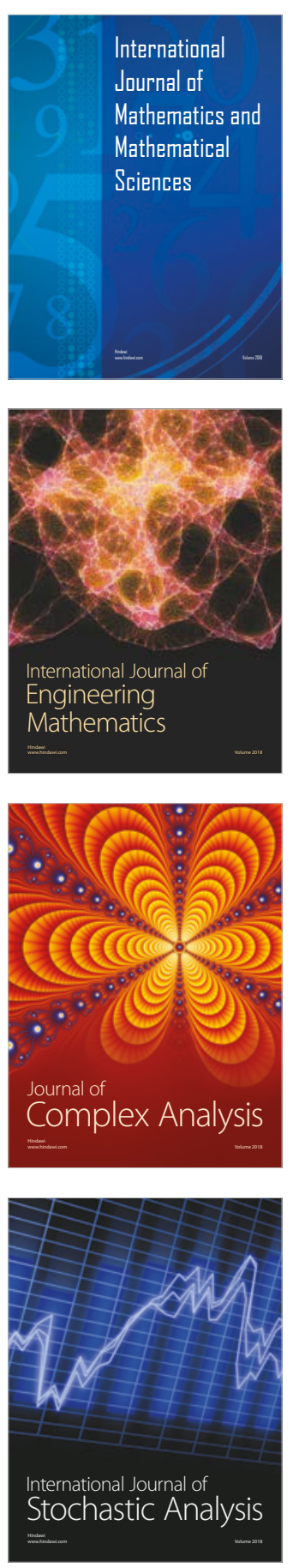
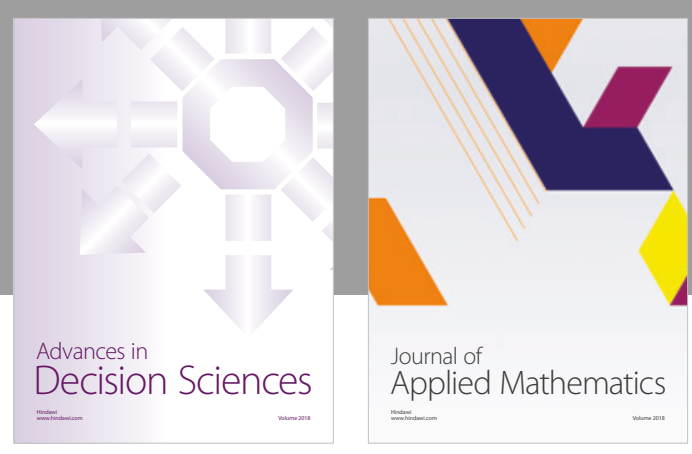

Journal of

Applied Mathematics
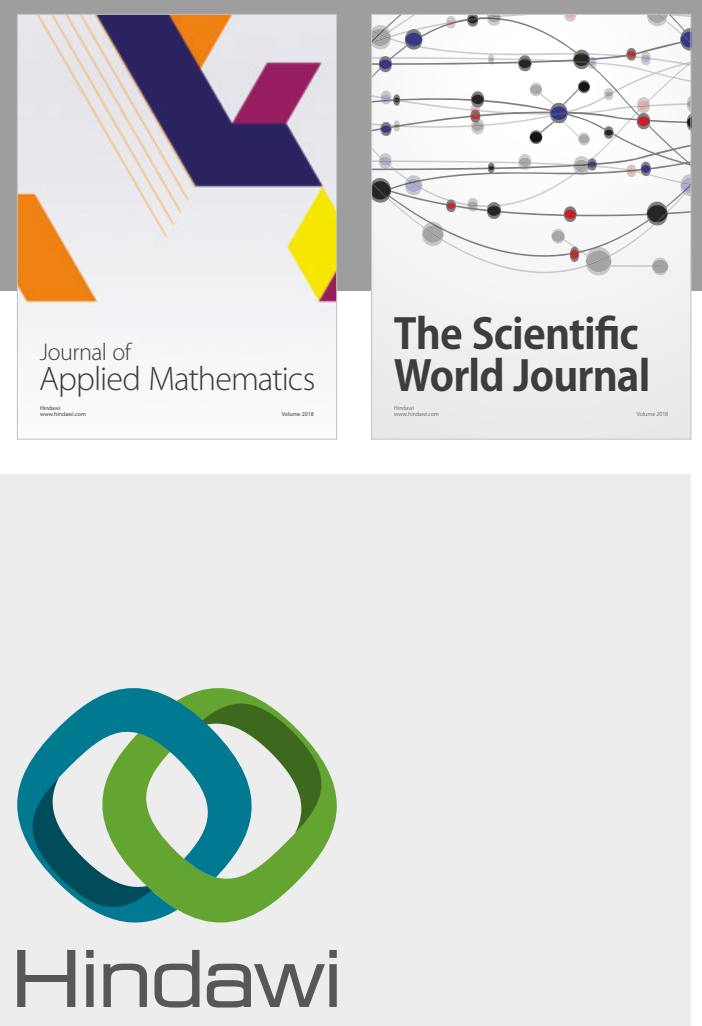

Submit your manuscripts at

www.hindawi.com

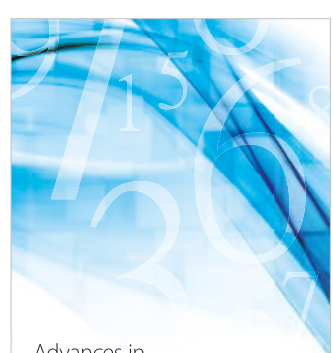

Advances in
Numerical Analysis
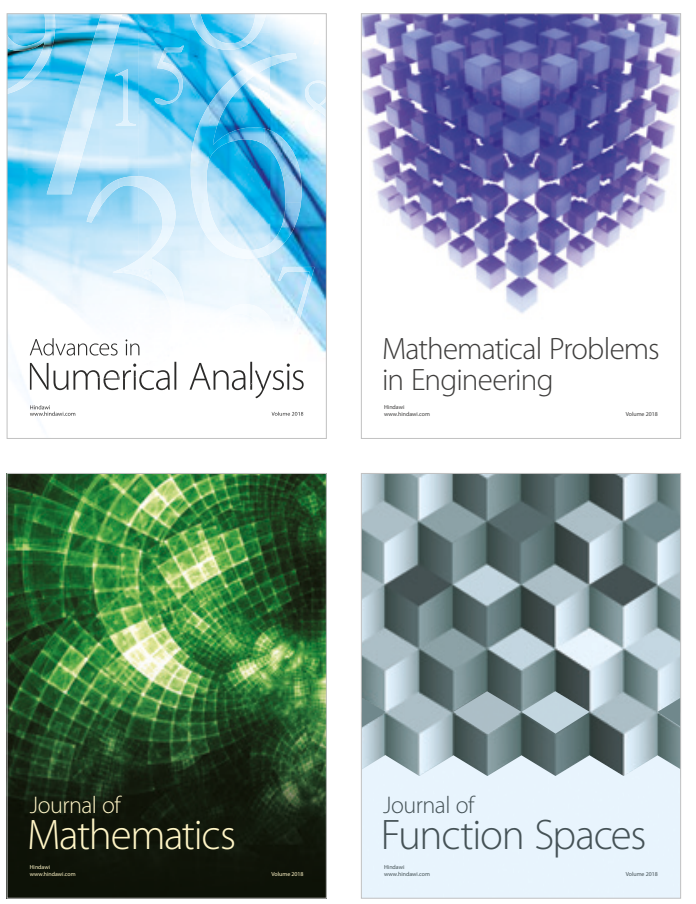

Mathematical Problems in Engineering

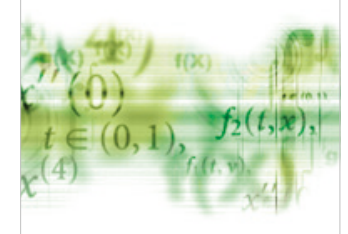

International Journal of

Differential Equations

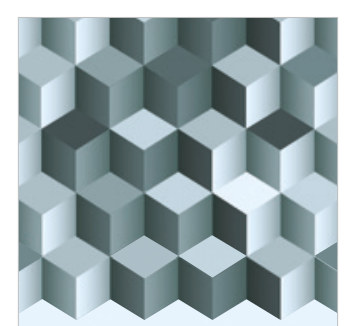

Journal of

Function Spaces

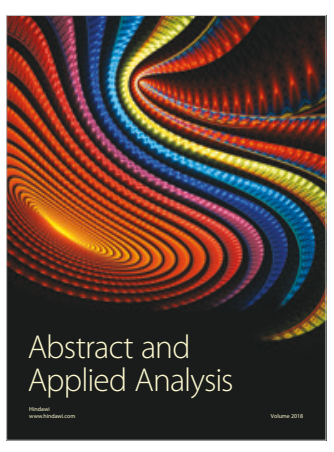

The Scientific

World Journal

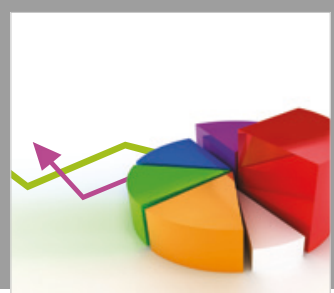

Journal of

Probability and Statistics
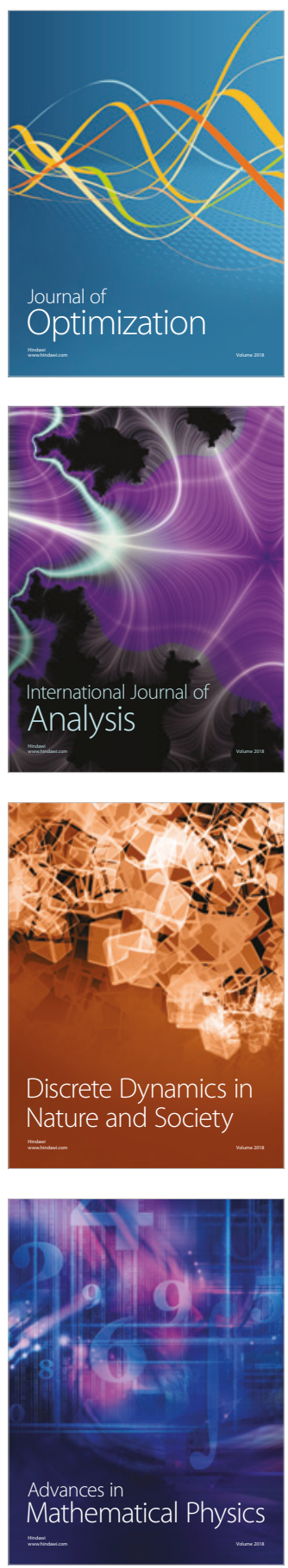